\title{
Intraocular Instillation Solution Dosage
} Form

National Cancer Institute

\section{Source}

National Cancer Institute. Intraocular Instillation Solution Dosage Form. NCI Thesaurus. Code C149610.

Liquid sterile preparation consisting of a solution intended to be instilled as drops into an internal part of the eye. 